\title{
PROFESSOR “DE DIREITO”: APOLOGIA AO PRINCÍPIO DA DIGNIDADE DA PESSOA HUMANA NO PROCESSO DE AVALIAÇÃO DA APRENDIZAGEM
}

\author{
Mauricio Silveira, Carmen Lúcia Dias, Helena Farias de Barros \\ Universidade do Oeste Paulista - UNOESTE. Mestrado em Educação, Presidente Prudente - SP. E-mail: \\ silveira@viaplus.com.br
}

\section{RESUMO}

O artigo tem como problema relacionar o processo de avaliação com a dignidade humana perpassando as posições de estudos acerca da importância da avaliação no ensino e na aprendizagem a demonstrar a possibilidade de ofensa a princípio constitucional que norteia o sistema jurídico. Por meio da evolução histórica da luta pelos Direitos Humanos com ênfase nos Direitos da Personalidade e do perfil enunciado pela doutrina do professor/educador atual, fez-se a análise documental. Traumas e desestímulo provocados pela utilização inadequada do processo de avaliação, fato corriqueiro que podem afrontar e ferir de morte o processo educativo. Chega-se ao conceito de avaliação que deve ultrapassar o simples cálculo aritmético para se converter em mais um instrumento no processo de ensino e de aprendizagem, desde que respeitada a dignidade da pessoa humana como princípio ético inseparável da função de educador.

Palavras- chave: Avaliação. Dignidade. Ética. Ensino. Aprendizagem.

\section{PROFESSOR "OF LAW OR THE RIGHT OF TEACHING": APOLOGY TO THE PRINCIPLE OF HUMAN DIGNITY IN THE PROCESS OF LEARNING ASSESSMENT}

\begin{abstract}
The article has the problem relate the evaluation process with human dignity bypassing the positions of studies about the importance of assessment in teaching and learning to demonstrate the possibility of offending the constitutional principle governing the legal system. Through the historical evolution of the struggle for human rights with emphasis on Personality Rights and profile statement by the doctrine of current teacher / educator, became the documentary analysis. Trauma and discouragement caused by improper use of the evaluation process, fact of life that can defy death and hurt the educational process. You get to the concept of evaluation that must exceed the simple arithmetic calculation to become another tool in the teaching and learning process, since it respected the dignity of the human person as ethical principle of inseparable function educator.
\end{abstract}

Keywords: Evaluation. Dignity. Ethics. Education. Learning. 
INTRODUÇÃO

O processo de aprendizagem é complexo, envolvendo e se desenvolvendo sob vários aspectos sociais, psicológico e físico, sendo de vital importância sua mensuração, que vem sendo utilizada com raízes aprofundadas na cultura do exame.

Seria ideal que esse processo garantisse o respeito ao educando por uma avaliação livre de coação, opressão e dominação, ingredientes que não contribuem para a aprendizagem em razão da quebra de confiança baseada no sofrimento do aluno.

No entanto se vê corriqueiramente esse instrumento tão importante para o processo de ensino e de aprendizado servir, na visão do educando, como mero instrumento de classificação e opressão, chegando ao ponto de criar traumas psicológicos e evasão escolar.

O objetivo desde trabalho é demonstrar a possibilidade de ofensa ao princípio da dignidade humana, insculpido na Constituição Federal quando o processo de avaliação não é utilizado adequadamente, sendo possível transformar em minutos um sonho em pesadelo ou o prazer da educação em frustração. Para tanto, tem como problema fazer a relação do processo de avaliação com o princípio da dignidade humana.

\section{METODOLOGIA}

Com base em pesquisadores na área da educação e do direito buscou-se a partir do conceito de Avaliação e da evolução histórica dos Direitos Humanos, demonstrar, por análise de documentos, implicitamente a relação entre os dois temas.

Parte-se do fato de a Avaliação ser um importante instrumento a ser utilizado no processo de ensino e da aprendizagem, possibilitando, por parte do professor e para o aluno a evidência dos seus progressos, servir por vezes, na visão do educando, como mero instrumento de classificação e opressão, chegando ao ponto de criar traumas psicológicos, além da evasão escolar; perpassa pela evolução dos Direitos da Personalidade, garantido pelo princípio da dignidade da pessoa humana, temas estudados no universo dos Direitos Humanos, para concluir com a relação entre os dois assuntos.

\section{AVALIAÇÃO COMO INSTRUMENTO DE CONFERÊNCIA DO APRENDIZADO}

Em sentido lato, pode-se dizer que a avaliação é o instrumento pelo qual se atribui valores referenciais (FERREIRA, 1995, p. 164), capazes de alimentar o sistema utilizado para verificação da aptidão do aluno para prosseguir o seu caminho. 
Para FERNANDEZ (2001, p. 71): “[...] quando se avalia um objeto, um fenômeno, um fato ou uma pessoa, o que se faz é atribuir um valor [...]".

A avaliação passou a ser utilizada para verificar, medir, classificar ou fazer um diagnóstico final. FERNANDEZ (2001, p. 72) afirma que: “[...] avaliar para atribuir uma nota ou um conceito, avaliar para rotular, separando as pessoas por categorias; avaliar excluindo pessoas, discriminando-as entre si".

É uma herança infeliz do século XIX, com origem na burocracia chinesa, ou seja:

Para evitar a constante ameaça de apropriação de cargos, impedir o clientelismo e a formação de monopólios de notáveis, o poder patrimonial da China imperial tomou estas medidas: nomeações a curto prazo, exclusão do cargo onde o funcionário tivesse parentes, vigilância mediante espiões, agregando, pela primeira vez na história, a exigência de exames. (BARRIGA apud. WEBER, 1983, p.791).

A avaliação deve ser utilizada para alavancar o processo de aprendizagem, para conferir o que se aprendeu, para estimular o aluno ou educando; para a averiguação da competência; condicionar a entrada e saída do sistema escolar e, ainda, controlar os professores, seja por si ou por seus administradores; definir o conteúdo, tornando-se elemento importante na gestão da aula ao fornecer informações sobre a imagem dos professores e os métodos pedagógicos utilizados. Como função de regulação, é capaz de melhorar os processos de aprendizagem proporcionando motivação e consciência dos sujeitos, além de ajudar no contexto organizacional (AFONSO, 2009).

$\mathrm{Na}$ cultura do exame, o aprendizado é conferido por meio da prova. Não obstante, o processo de avaliação deve ser compreendido como análise do aprendizado em busca do estado ideal, observados os parâmetros pré-existentes.

Não se pode utilizar a famosa indagação: Que nota foi a sua? Deve ser substituída por: Aprendeu? Por que não acertou? Como fazer para que todos se apropriem do conhecimento? Por que o método não funcionou? Que dificuldades o aluno encontrou?

Avaliar é julgar o aprendizado de alguém numa escala de valores; consiste na coleta de dados quantitativos e qualitativos e na interpretação dos resultados com base em critérios préestabelecidos pelo programa do currículo e do ensino e, como se busca modificações nos padrões de comportamento do estudante, também é o modo de averiguação do grau que essas modificações vão ocorrendo (HAYDT, 1997).

Para Michael Scriven (apud HAYDT, 1997, p. 12), é um procedimento metodológico onde se coleta e combina dados numa escala de critérios para classificações comparativas ou numéricas. É 
preciso avaliar "não apenas o grau de consecução dos objetivos estabelecidos, mas também os próprios objetivos e as outras conseqüências não previstas" (HAYDT, 1997, p. 12).

São várias as dimensões do conceito de avaliação, seja como método de processamento de dados, seja como auxilio no esclarecimento das metas e objetivos educacionais e, ainda, como conferência do desenvolvimento do aluno, como controle de qualidade, e, pode ser utilizada para verificação dos procedimentos e sua eficácia em razão dos objetivos educacionais (BLOOM; HASTINGS ; MADAUS apud HAYDT, p. 13).

Para BOTH (2012), avaliar é aplicar um método, utilizar um instrumento, não pode existir por existir, para satisfação de um sistema de pontuação, mas sim ser utilizada como um recurso do de ensinar e aprender, ou aprender simplesmente.

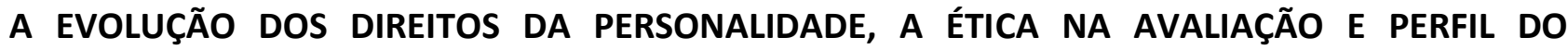 EDUCADOR}

A dignidade da pessoa humana está insculpida como princípio constitucional em nosso ordenamento jurídico (artigo 1으, inciso III, da Constituição Federal). Surgiu como conseqüência do reconhecimento dos Direitos Humanos Fundamentais.

Historicamente, nossa legislação cuidou de tutelar os direitos patrimoniais, enfatizando a existência humana frente o aspecto patrimonial e pouco se preocupou o aspecto humano, ou seja, da pessoa enquanto gente. O direito codificado deixou de proteger a personalidade para dar maior ênfase aos aspectos patrimonialísticos da existência humana, criando um vácuo que acabou sendo preenchido pela Constituição Federal (CORTIANO JÚNIOR, 2000).

O reconhecimento da importância do homem como o centro e a razão do ordenamento jurídico decola com a consolidação do cristianismo $^{1}$, sem prejuízo de, no período medieval, se iniciar o raciocínio inerente aos direitos individuais, mediante contratação e concessão do poder feudal (PEÑA, 1947, p. 342. apud JABUR, 2000. p. 34/35).

Com o Renascimento e com o surgimento da Escola de Direito Natural, no século XVII, modifica-se o raciocínio, entendendo-se que os direitos individuais seriam inatos, preexistentes e imediatos, ou seja, ao Estado não cabia criá-los, mas tão só declará-los. Diante desse sistema antropocêntrico, profundamente individualista, insuflaram-se as reivindicações atuais, sendo a dignidade sua célula principal e foi em França que ferveram movimentos que apregoavam o ser

\footnotetext{
${ }^{1}$ Essa sistemática, "o homem como centro da organização social”, teve sua origem na filosofia que precedeu e acompanhou a Revolução Francesa; "o período do jus naturalismo e do iluminismo". "... o direito objetivo passou a ser considerado criação do sujeito, sendo, portanto, o direito subjetivo, reflexo das mais diversas manifestações da personalidade humana". O direito subjetivo, por seu turno, passou a ser visto como "atributo" do ordenamento, configurando-se o desprestígio da pessoa humana, "reduzida a simples elemento da relação jurídica". Posteriormente, no século XIX, com forte influência do liberalismo em busca do "mundo da segurança", as codificações dos sistemas jurídicos acabaram deixando de lado o interesse pessoal para assegurar os bens do homem, motivo pelo qual participava da relação jurídica. (MEIRELLES, 2000, p. 87).
} 
humano como sujeito de direitos indestacáveis cuja existência não poderia depender de beneplácito do Estado, sendo em 1789 elaborados os cahiers de doléances (cadernos de queixas). Luiz XVI, temendo discordar dos representantes do povo francês, acabou por aquiescer de maneira oblíqua, em 5 de outubro do mesmo ano (JABUR, 2000).

Seguiu-se a Declaração dos Direitos do Homem e do Cidadão (Déclaration des droits de I'homme et du citoyen), que, sem prejuízo de não assegurar precipuamente os direitos da personalidade, garantiu uma emancipação política do homem frente ao Estado, afiançando sua liberdade e respeito, após vários movimentos que buscaram o reconhecimento desses direitos, passaram a ser garantidos constitucionalmente. Após mais de mil anos, o termo dignidade alicerça os seguimentos da sociedade.

No processo educativo esse tema perpassa pelo terreno da ética. Assim como o pesquisador deve se preocupar com a ética e os sujeitos da pesquisa, o educador deve ter a mesma preocupação em relação ao educando (FERNANDES, 2001).

É nesse sentido a lição de BERBEL (2011, p. 173):

A avaliação da aprendizagem é, talvez, o momento pedagógico mais crítico e mais imbuído de elementos éticos, pois é o momento que nós professores julgamos, é o momento em que podemos definir a vida acadêmica do aluno. Com nossas atitudes, podemos ter um comportamento que revela nosso respeito, nosso compromisso ético com a aprendizagem e o crescimento dos alunos, ou ao contrário, podemos ter comportamentos que revelam arbitrariedades, abusos de poder, uso de punições, injustiças, protecionismos, falta de consideração e de respeito, que resultam em prejuízos dos alunos.

O compromisso ético fixa o compromisso com o desenvolvimento do educando para auxiliá-lo, não interessando simplesmente um veredicto (FERNANDES, 2001).

O aluno merece ser avaliado em seu todo, deve ter conhecimento de como desenvolver suas atividades para atingir o rendimento escolar, com direito de acompanhamento de educador capaz de identificar suas dificuldades.

Se a escola é democrática e se seu objetivo é promover a transformação da sociedade; o educando deve ser capaz de compreender e valorar suas diferenças.

Para HADJ:

[...] o maior risco que o educador corre é o de sentir prazer em dominar, de se sentir em posição superior, de manter o outro em situação inferior. $O$ educador foge à ética quando humilha os educandos que avalia, rotulando-os, por exemplo, de 'zero à esquerda'; quando se sente importante diante da fraqueza do outro, quando em vez de contribuir para o crescimento, destrói a vontade de aprender. (apud FERNANDES, 2002, p. 44). 
Na avaliação não deve ser classificatória e excludente. Como afirma FERNANDES:

Reconhecer, com Paulo Freire (1981) que não podemos pensar por nossos alunos, nem para os nossos alunos e principalmente, sem nossos alunos, é um passo fundamental para que se possa agir nesse sentido. Em essência, avaliamos para promover a aprendizagem de nossos alunos, não apenas para cumprir normas institucionais ou mesmo à lei vigente. Leis e normas são conseqüências da decisão de educar e não sua causa (FERNANDES, 2001, p. 81).

Avaliar para respeitar as exigências legais e burocráticas dos sistemas de ensino não significa ignorar o compromisso com a aprendizagem, pois:

[...]a avaliação serve de baliza que orienta o educador na sua docência e não como instrumento de punição ou premiação, de reprovação ou aprovação [...] não necessita o professor se afligir pelo fato de não estar empregando à risca concepções e métodos avaliativos de renomados teóricos de avaliação. Se a sua concepção e método de avaliação correspondem à finalidade educativa, é o que mais importa (BOTH, 2002, p. 20-21).

As seguintes novas-antigas ponderações impõem o perfil do educador:

[...] o bom professor certamente não é aquele que muito reprova ou aprova a todos; [...] toma as medidas para que a aprendizagem aconteça...; [...] sabe desviar-se da cultura da reprovação; [...] sabe avaliar ensinando e ensinar avaliando; [...] tem consciência do ato de ensinar; [...] se preocupa em dar sentido aos conteúdos escolares, aproximando-os da realidade vivida pelos alunos; [...] sabe que a educação é a chave para a transformação da sociedade; [...] sabe respeitar o jeito de ser, o ritmo e o conhecimento dos seus alunos; [...] sabe reconhecer na educação o melhor meio para a conquista da cidadania; [...] sabe trabalhar com alunos que manifestam maiores aptidões em uma disciplina do que em outra; [...] sabe identificar e contornar os principais fatores que dificultam a aprendizagem; o educador do futuro é aquele que sabe ensinar, sim, mas que prefere trabalhar com o aluno e fazê-lo trabalhar e produzir (ensino com investigação); [...] sabe contribuir na elaboração de projeto políticopedagógico para a sua unidade escolar e desenvolve atividades a partir dele; [...] o bom professor é aquele que também sabe valorizar o que o aluno sabe e não principalmente o que não sabe; [...] busca permanentemente o próprio aperfeiçoamento; [...] percebe que os tempos mudam [...] o bom professor e o educador do futuro primam pela alegria de educar (BOTH, 2002, p. 20-21).

\section{RESPEITO ÀS DIFERENÇAS INDIVIDUAIS}

Por serem dotadas de personalidade, as pessoas manifestam-se de modo distinto diante de situações iguais ou semelhantes. (FIERRO apud BERBEL, 2001, p. 158).

Para Waldeciria Souza da Costa, os aspectos psicológicos não cognitivos como, a ansiedade, as expectativas de controle e o conceito de si mesmos, podem provocar um estado de ânimo negativo traduzido pelo medo, pelo nervosismo e a baixa estima (COSTA apud BERBEL, 2001) 
A autora ainda sustenta que conhecida como "ansiedade de prova ou exame", a prevenção deve ser feita pelo educador e, por muitas vezes, com atitudes simplórias se obtém êxito, como por exemplo, autorizar os alunos a comentar a prova uns com os outros. Ainda afirma que anomalias devem ser evitadas, corrigidas e acompanhadas, para que não interfiram na avaliação voltada não só para a conferência do aprendizado, mas, para identificar falhas no procedimento metodológico, devendo se evitar comportamentos como aplicar provas com conteúdo mais aprofundado ou utilizá-la em tom de ameaça.

Ainda chama a atenção para o fato de que o comportamento ético do educador tem maior propriedade para se alcançar os objetivos, podendo ser identificado com procedimentos que acalmam o aluno como demonstração de amizade e comentários acerca dos erros e dos acertos da turma.

O aluno tem muito a ajudar na avaliação, mas é necessário que conheça os objetivos, perceba a boa fé do professor e o seu comprometimento.

O erro na avaliação sinaliza a evolução do aluno para o saber, ajuda a identificar as dificuldades; não se trata de tentar encontrá-las, mas de buscar os mecanismos para recuperar os repetentes, criar, pesquisar nas fontes, buscar autoridade e autonomia, portanto: "avaliar, dar nota, valorizar o processo e o produto do sujeito passa a ser um grande desafio para a escola" (BORGES, 2000, p. 64).

\section{CONCLUSÕES}

O processo de ensino há de se moldar diante da nova concepção de educador, que ao desempenhar o seu papel, considerando o educando como o centro da atenção, afastará a idéia de dominação do conhecimento outrora adotado e adorado.

O papel da escola deve ser condizente com a exigência social, oferecendo significativas contribuições para a garantia da cidadania e da democracia.

Tem-se que o conceito de avaliação deve ultrapassar o simples cálculo aritmético para se converter em mais um instrumento, que devidamente utilizado, pode ser incorporado no processo de ensino e de aprendizagem, desde que respeitada a dignidade como princípio ético e inseparável da função de educador.

$\mathrm{Na}$ escola atual não pode existir "dinossauros" da educação, por isso, o professor deve acompanhar a evolução e ter em mente o conceito atual de Dignidade da Pessoa Humana, respeito aos Direitos da Personalidade, sendo inadmissível raciocinar avaliação, ensino, aprendizagem como há MIL ANOS. 


\section{REFERÊNCIAS}

AFONSO, A. J. Avaliação educacional: regulação e emancipação. 4 ed. São Paulo: Cortez, 2009. BERBEL, N. A. N. et al. Avaliação da aprendizagem no ensino superior - um retrato em cinco dimensões. Londrina, Paraná: UEL, 2001.

BOTH, I. J. Avaliação-ensino e projeto pedagógico: parceiros em avaliação institucional. Módulo IV. Presidente Prudente, São Paulo: UNOESTE, 2002.

BORGES, A. L. et. al. (Por) uma educação com alma. Petrópolis: Vozes, 2000.

CORTIANO JUNIOR, E. Repensando fundamentos de direito civil brasileiro contemporâneo. Alguns apontamentos sobre os chamados direitos da personalidade. Rio de Janeiro: Renovar, 2000.

FERNANDES, C. T. Concepções teóricas de avaliação - módulo I. Presidente Prudente, São Paulo: UNOESTE, 2001.

. Tratamento dos dados da avaliação e uso das informações - módulo V. Presidente Prudente: Unoeste, 2002.

FERREIRA, A. B. de H. Novo dicionário da Língua Portuguesa. Rio de Janeiro : Nova Fronteira, 1ạ ed., 1995.

HAYDT, R. C. C. Avaliação do processo ensino-aprendizagem. São Paulo: Ática, 1997.

JABUR, G. H. Liberdade de pensamento e direito à vida privada. São Paulo: Revista dos Tribunais, 2000.

MEIRELLES, J. Repensando fundamentos de direito civil brasileiro contemporâneo - 0 ser e o ter na codificação civil brasileira: do sujeito virtual à cláusula patrimonial. Rio de Janeiro: Renovar, 2000.

WEBER. M. Economia y Sociedade. México: Fondo de Cutura Econômica, 1983. 